\title{
VIVÊNCIA DE PUÉRPERAS COM FILHOS RECÉM-NASCIDOS HOSPITALIZADOS ${ }^{a}$
}

\author{
Experience of Puerperas with \\ Hospitalized Newborn Children \\ Vivencia de Puérperas con Niños \\ Recién Nacidos Hospitalizados
}

Maria Adelane Alves Monteiro

Ana Karina Bezerra Pinheiro

Ângela Maria Alves e Souza

\section{Resumo}

Estudo exploratório descritivo, de abordagem qualitativa, com objetivos de: caracterizar as puérperas que acompanham 0 filho recém-nascido hospitalizado e conhecer a vivência destas puérperas na hospitalização do filho. A coleta de informações ocorreu em uma casa de apoio, anexo de um hospital filantrópico de Sobral-CE, em abril de 2005. Utilizou-se entrevista semiestruturada. Participaram do estudo nove mães. 0 referencial teórico de análise foi a Teoria do Vínculo de Pichon-Rivière. Identificamos as características socioeconômicas e obstétricas das puérperas e analisamos a experiência destas na hospitalização do filho recém-nascido, mediante investigação psicossocial e sociodinâmica. 0 estudo revelou sentimentos expressados pela mãe, o vínculo mãe-filho e as relações com a família e o grupo. A compreensão das relações e dos vínculos estabelecidos pela mãe com seus familiares e com o grupo no qual está inserida configura-se em um dos primeiros passos para que os enfermeiros possam favorecer a adaptação das mesmas ao processo de hospitalização do filho recém-nascido.

Palavras-chave: Período Pós-Parto. Recém-Nascido. Hospitalização. Enfermagem.

\section{Abstract}

This is an exploratory study with qualitative approach that has as objectives: to characterize the puerpera that accompany the hospitalized newborn child and to know the experience of these women in the child's hospitalization. The collection of information happened in a support house, enclosure of a philanthropic hospital of Sobral - Ceára (Brazil), in April of 2005. It was used semi-structured interview. Nine mothers participated in the study. The theoretical referential of analysis was the Pichon-Rivière Bond Theory. We identified the socioeconomic and obstetric characteristics of the puerpera and we analyzed the experience of these women in the newborn child's hospitalization, by psychosocial and social dynamics investigation. The study revealed feelings expressed by the mother, the bond mother-son, and the relationships with the family and the group. The understanding of the relationships and of the established bonds for the mother with their family and with the group in which is inserted it is configured in one of the first steps that the nurses can favour the adaptation of the same ones to the situation.

\section{Keywords:}

Postpartum Period. Newborn. Hospitalization. Nursing.

\section{Resumen}

Estudio exploratorio descriptivo de acercamiento cualitativo, con los objetivos de: caracterizar las puérperas que acompañan el hijo recién nacido hospitalizado y conocer la vivencia de éstas puérperas en la hospitalización del hijo. La colecta de informaciones ocurrió en una casa de apoyo, cerca de un hospital filantrópico de Sobral - Ceará (Brasil), en abril de 2005. Fue usada la entrevista media estructurada. Participaron del estudio nueve madres. El referencial teórico de análisis fué la Teoría del Vínculo de Pichon-Rivière. Identificamos las características socio-económicas y obstétricas de las mujeres en período posparto y analizamos la experiencia de éstas en la hospitalización del hijo recién nacido, por la investigación psicosocial y sociodinámica. El estudio reveló sentimientos expresados por la madre, el vínculo madre-hijo, las relaciones con la familia y el grupo. La comprensión de las relaciones y de los vínculos establecidos por la madre con sus parientes y con el grupo en que se inserta, se configura en uno de los primeros pasos para que las enfermeras puedan favorecer la adaptación de las mismas a la situación.

Palabras clave: Periodo de Posparto. Recién Nacido. Hospitalización. Enfermería. 


\section{INTRODUÇÃO}

No município de Sobral-CE, foi implantado um Programamodelo de Atenção à Saúde Materno-Infantil, objeto da Cooperação Técnica não Reembolsável-ATN/SF-6063-BR, estabelecida entre a Confederação das Misericórdias do Brasil (CMB) e o Banco Interamericano de Desenvolvimento (BID), o qual assistia gestantes de risco por toda a gravidez, parto e puerpério.

Funcionou de 1998 a 2004, em um hospital filantrópico de referência. Em 2001, o mesmo projeto implantou a "Casa da Mamãe", um local para abrigar puérperas residentes em outras localidades e cujos recém-nascidos necessitavam de hospitalização na unidade neonatal de cuidados intermediários, a qual não dispõe de estruturafísica para que as mães permaneçam dentro da unidade acompanhando seus filhos internados.

Essas mães vivenciam uma experiência nova ao serem alojadas nesse local, pois, até então, as crianças que necessitassem de hospitalização eram separadas de suas mães que só as viam por ocasião da visita. 0 que mais chama a atenção é a forma como cada uma reage diante das circunstâncias que envolvem estar longe da família, com filho hospitalizado e ainda atravessando uma fase importante do ciclo gravídico-puerperal que é o puerpério.

Nesse período, ocorre uma série de alterações anatômicas e fisiológicas no corpo da puérpera, repercutindo não somente em nível endócrino e genital, mas no seu todo. A mulher, neste momento, como em todos os outros, deve ser vista como um ser integral, não excluindo seu componente psíquico ${ }^{1}$. As situaç̃̃es por ela vividas durante a gestação, parto e puerpério requerem ajustamentos e reestruturações, tornando-a vulnerável à manifestação de crises².

A transcendência de uma condição (ser mulher) à outra (ser mãe) é um processo de crescimento e amadurecimento que exige um olhar diferenciado do profissional de saúde. São vivenciadas experiências que traduzem: dar conta do nascimento do bebê e de suas obrigações, assumir a responsabilidade por ele, a sua vulnerabilidade, chegar ao limite de sua capacidade, extravasar seus sentimentos e perceber-se como mãe ${ }^{3}$.

Portanto, o puerpério por si só já pressupõe um contexto problemático, levando-se em conta a complexidade dos fatores referidos anteriormente e que fazem parte desse período. Somando-se a tudo isso, tem-se a distorção das expectativas do casal diante do nascituro, pois na maioria das vezes essa criança é esperada e idealizada, e o fato de necessitar ser hospitalizada pode causar muito sofrimento. Logo, é possível presumir que diversos tipos de sentimentos, comportamentos e atitudes possam emergir dessa situação.

A hospitalização de um filho resulta em sofrimento para a mãe com repercussão na dinâmica familiar. As genitoras deixam de cuidar de si por dedicação a sua prole. Essa abdicação e as preocupações decorrentes da ausência do lar desencadeiam sinais evidentes de desgaste físico e psicológico ${ }^{4-5}$.

Assim, a problemática que envolve a hospitalização de um filho recém-nascido faz com que a vivência do período puerperal para essas mães se torne mais difícil. Estas mães, ao experimentarem a ausência de seus filhos no pós-parto, desencadeiam uma instabilidade física e emocional, necessitando de apoio da equipe multiprofissional, principalmente da enfermagem. Este cuidado trata de uma assistência capaz de estimulá-las positivamente diante das dificuldades, minimizando os problemas emocionais mais sérios e suas repercussões em sua vida social e interpessoal ${ }^{6}$.

Desta forma, este estudo tem como objetivos: identificar o perfil de puérperas que acompanham o filho recém-nascido hospitalizado e conhecer a vivência destas puérperas na hospitalização do filho.

\section{METODOLOGIA}

Trata-se de um estudo exploratório descritivo com abordagem qualitativa, realizado no período de abril de 2005, em uma Casa de apoio com a denominação de "Casa da Mamãe", a qual faz parte de um hospital filantrópico de referência secundária e terciária para a região norte do estado, localizado em Sobral-CE.

Fizeram parte do estudo nove mães que estavam na Casa no período da coleta de dados e aceitaram participar da pesquisa, assinando o Termo de Consentimento Livre e Esclarecido. Para manter o anonimato das participantes, utilizamos nomes de pássaros como pseudônimos. 0 instrumento para coleta de dados empregado foi um roteiro de entrevista semi-estruturada, e contamos com o recurso do gravador. Dentre as entrevistadas, houve uma que não soube responder a algumas perguntas; portanto, colhemos os dados complementares do prontuário obstétrico.

As falas foram fidedignamente respeitadas, transcritas e analisadas, preservando a identidade dos sujeitos, assim como dando total credibilidade aos depoimentos colhidos. A análise e interpretação das informações se deram mediante aplicação da técnica fundamentada na comparação das respostas entre indivíduos ${ }^{7}$, percorrendo-se os seguintes passos: leitura das respostas aos questionamentos apresentados, buscando obter uma visão geral do material; identificação e delimitação das unidades de significados em temas da investigação. Procuramos preservar, na descrição, o conteúdo específico dos fenômenos, focalizando seus aspectos fundamentais e produzindo a descrição dos seus significados essenciais para o grupo pesquisado, a fim de representar o fenômeno na sua totalidade ${ }^{7}$.

Como base teórica para o estudo, nos fundamentamos na Teoria do vínculo ${ }^{8}$, no sentido de conhecer as relações interpessoais e a sua influência sobre o surgimento de tensões ou desajustes que podem emergir durante a experiência da puérpera na hospitalização de seu filho recém-nascido. Esta necessidade partiu do fato de que todas as mães pesquisadas vivenciavam a separação de seu bebê ou rompimento do vínculo com a família de origem. Vínculo diz respeito a uma estrutura particular criada pelo indivíduo a cada momento ao se relacionar com os outros. Logo, o vínculo é sempre uma relação social, mesmo sendo com uma só pessoa, pois através da relação do sujeito com essa pessoa, pode-se deduzir como são os vínculos com outros objetos em um determinado tempo e espaço ${ }^{8}$.

A Teoria propõe estudar a formação dos vínculos a partir de três dimensões: o próprio indivíduo, o seu grupo e a 
instituição ou sociedade, permitindo, desta forma, três tipos de análise: a psicossocial, que parte do indivíduo para o seu meio exterior, a sociodinâmica, que analisa o grupo como estrutura, e a institucional, que abrange todo um grupo, instituição ou mesmo o contexto de um país como objeto de investigação $0^{8}$. Os dois primeiros tipos são apresentados como categorias analíticas neste estudo, pois se referem às relações ou vínculos percebidos entre os sujeitos do estudo - as puérperas e seus objetos externos - família, amigos, filho e outros. $\mathrm{Na}$ investigação psicossocial, analisamos a expressão de sentimentos da mãe diante da hospitalização do filho, enquanto que no estudo sociodinâmico analisamos as tensões resultantes das relações entre os membros que configuram a estrutura familiar e entre o grupo (de mães) dentro do qual a puérpera está inserida.

A investigação respeitou os princípios bioéticos postulados na Resolução 196/96 do Conselho Nacional de Saúde ${ }^{9}$, os quais se referem à: autonomia, beneficência, não-maleficência e justiça. Solicitamos inicialmente autorização da instituição para realização da pesquisa, e o projeto deste estudo foi submetido ao Comitê de Ética do Complexo Hospitalar da Universidade Federal do Ceará, recebendo parecer favorável.

\section{ANÁLISE E DISCUSSÃO DAS INFORMAÇÕES}

Entendemos que cada mãe, mesmo vivenciando situações semelhantes, possui suas peculiaridades. Portanto, consideramos importante identificar o perfil das mães com filho recém-nascido hospitalizado, compreendendo que este objetivo configura-se em um passo importante para conhecer a vivência das mulheres que passam por esta experiência.

\section{Perfil da mãe que acompanha 0 filho recém-nascido hospitalizado}

Realizamos uma análise das informações obtidas com as participantes por meio de entrevista e complementadas com dados do prontuário obstétrico, identificando as seguintes características:

\section{Características socioeconômicas}

Quatro mães estavam ainda na fase da adolescência (faixa etária de 10 a 19 anos, segundo a OMS), demonstrando o quadro atual de crescimento no número de mulheres que estão engravidando cada vez mais cedo. Entre 1993 e 1998, observou-se um aumento de 31\% no percentual de parto em meninas de 10-14 anos, atendidas pela rede do Sistema Único de Saúde (SUS) ${ }^{10}$.

Talvez também por esse motivo, todas as mães haviam deixado de estudar, sendo que a maioria não tinha concluído o ensino fundamental e apenas uma mãe tinha concluído o ensino médio; no entanto, apenas uma puérpera era analfabeta. Isto vem revelar a situação educacional em que nosso país se encontra. Mesmo que o índice de analfabetismo tenha diminuído, muitos brasileiros ainda não conseguem dar continuidade a sua formação e uma pequena minoria tem acesso ao ensino superior.

0 abandono da escola é a maior modificação na vida das adolescentes grávidas (68\%), ocorrendo, na maioria dos casos, no início da gravidez, revelando o medo que as mesmas têm de não serem aceitas ${ }^{11}$. Esta realidade está diretamente ligada ao fato de que quase metade das puérperas tinha renda familiar menor que dois salários mínimos, duas tinham o marido que estava desempregado e nenhuma delas tinha renda que ultrapassasse dois salários mínimos. A única puérpera que conseguiu concluir o ensino médio era também a única que tinha um emprego fixo.

Quanto ao estado civil, seis mães diziam-se casadas; no entanto, entre as que se denominavam "juntas", na verdade viviam na condição de solteiras. Estas puérperas moravam na casa de seus pais, o que geralmente, pode interferir na construção de uma maternidade/paternidade responsável. 0 que possivelmente ocorre é que a gravidez que não foi planejada leva, muitas vezes, ao sentimento, mesmo que momentâneo e inconsciente, de "união". Esse sentimento se acentua com o nascimento do filho, e o casamento torna-se uma obrigação natural com a chegada do bebê.

Seis mães eram procedentes de outros municípios, residindo na zona rural. Isto reforça o papel do hospital de ser referência secundária e terciária para muitos municípios da região, além de alertar-nos para o fato de que as barreiras geográficas e socioeconômicas também limitavam o número de visitas e outros contatos destas mulheres com seus familiares. Esta situação por si só é geradora de muito estresse, pois a distância da familia e a falta que isto representa foram relatadas pelas participantes do estudo.

Apenas uma mãe parecia não seguir nenhuma religião, uma era evangélica e todas as restantes diziam-se católicas. Muitas das participantes do estudo em suas falas citaram sentimentos de fé, esperança e que acreditavam que Deus iria recuperar seus filhos, e outras até atribuíam o fato da hospitalização do bebê à vontade de Deus.

Percebemos que o perfil de mãe adolescente, proveniente da zona rural, com baixo grau de instrução, renda familiar precária e residente com sua família de origem, só agrava a experiência de ser puérpera com um filho hospitalizado.

\section{Características obstétricas}

Quatro mães eram primíparas, apenas uma tinha engravidado pela quarta vez, e as demais eram secundíparas. Isto vem reforçar como a vivência de ter um filho recém-nascido hospitalizado foi experienciada pela primeira vez por estas mulheres.

Os diagnósticos iniciais na admissão das gestantes foram: placenta prévia (1), hemorragia do $2^{\circ}$ trimestre de gestação (1), doença hipertensiva específica da gravidez (2), trabalho de parto prematuro(3) e rotura prematura de membrana (2).

Apenas uma mãe teve parto cesáreo, e o restante das participantes do estudo, parto normal. Também apenas uma teve seu filho a termo, e todas as outras deram à luz prematuramente. Portanto, a prematuridade foi o principal motivo de hospitalização dos bebês destas mães.

Todas as mães responderam que realizaram acompanhamento pré-natal, e, a respeito da mãe que não tinha condições de responder, foi detectada, no prontuário, a realização dessa assistência. Isso nos leva a questionar a alta frequeência de prematuridade entre as participantes, já que o trabalho de parto prematuro pode ser atribuído a infecções urinárias e genitais, detectáveis durante o pré-natal12. 
Acreditamos que condições como estar na primeira gravidez, o aparecimento de intercorrências durante a gestação, antecipando o momento do parto, assim como a qualidade da assistência pré-natal recebida pelas mães nessa fase, podem interferir na adaptação das mesmas à experiência de permanecer com o filho hospitalizado logo após o nascimento.

\section{A experiência vivida pela mãe na hospitalização do seu filho recém-nascido}

Percebemos, pelas falas das participantes apresentadas a seguir, que vivenciar a hospitalização do filho envolve questões que vão além da própria recuperação do bebê, evidenciando a complexidade da experiência. Desta forma, no cuidado da mãe com filho hospitalizado, não devemos considerar apenas a condição de saúde do recém-nascido, mas toda a rede de relações que se forma entre as mães e os objetos que podem influenciar esse processo.

Aspectos psicossociais: sentimentos envol vidos no processo da hospitalização

Apesar de muitas vezes não se tratar de uma gravidez planejada ou mesmo desejada, o que é comum entre adolescentes, o parto antes do termo e a conseqüente hospitalização do filho é considerado algo inesperado, podendo repercutir em sentimentos negativos. Entretanto, geralmente durante todo o período da gravidez, a mãe sonha com um bebê saudável, vivenciando, a partir do momento do parto, outra realidade daquela esperada:

... Nunca tinha nem passado por isso nem nada, não tinha nem noção, nem esperava que ele nascesse de sete meses...nunca tinha passado pela minha cabeça e só vim acreditar mesmo depois que ele estava lá (mãe-'Bem-te-vi').

... Desta vez é diferente porque eu queria estar com ele (segundo filho) em casa assim que ele nasceu...porque foi planejado..ele (companheiro) queria muito um filho...(mãe-'Gaivota').

A ocorrência do nascimento prematuro do bebê, aliada à separação mãe-filho, gera uma situação conflitante na puérpera, a qual se sente preocupada e incapaz de entender 0 que está acontecendo com ela e com o filho ${ }^{13}$. Ressaltamos que a prematuridade foi a principal causa de internação dos bebês das participantes do estudo.

A notícia inesperada e o entendimento da possibilidade de que o filho poderia vir a ficar hospitalizado trouxe a essas mães sentimentos de medo (de perder o filho), angústia e não-aceitação diante da situação:

... Não me disseram direto não. Primeiro me disseram que ela tinha nascido cansada e ia para a incubadora... fiquei com uma coisa ruim no peito, uma angústia, mas depois passou...fui me acostumando (mãe-'Sabiá').

... Quando soube que ela ia nascer de 7 meses, eu não queria aceitar...fiquei com muito medo, porque para mim eu achava que ela ia nascer e não ia sobreviver...eu tinha que arrumar um jeito para não ter ela naquele momento...o meu medo era perder ela...eu estava tão tensa...(mãe-'Andorinha').

No momento em que a mãe é informada de que o bebê necessitará ficar internado na Unidade de Terapia Intensiva Neonatal, é ocasionada uma tristeza pelo fato de não saber o que acontecerá com o filho e também porque o próprio parto já a deixa muito fragilizada ${ }^{14}$. As repercussões desta situação tornam-se mais acentuadas quando o bebê está afastado de sua mãe ${ }^{15}$.

0 vínculo primeiro da vida humana é o intra-uterino, que se caracteriza por ser uma relação de objeto não-diferenciado, isto é, um vínculo parasitário, pois o feto depende totalmente da mãe. Essa relação evolui e passa a ser simbiótico ou siamésico. Quando o vínculo é siamésico, a criança experimenta a separação da mãe como se acarretasse a morte das duas, sendo esta a forma mais angustiante de vínculo ${ }^{8}$. Desta forma, o próprio fato do nascimento já ocasiona uma separação dolorosa para a mãe e o bebê. Somando-se a esta condição, 0 fato da hospitalização intensifica ainda mais o sofrimento para ambos, podendo acarretar reações de desajustes.

Ao ver o filho pela primeira vez na unidade neonatal, as mães referiram sentimentos ambivalentes: positivos, por estarem vendo o filho vivo, e negativos, por permanecerem separadas dele:

Eu estava com medo de entrar no berçário e olhar...eu fiquei com uma coisa assim!...fiquei emocionada por estar vendo ela, e ao mesmo tempo triste por não ter ela em meus braços... (mãe-'Andorinha').

Esse fato pode ser entendido à medida que se compreende o vínculo como uma estrutura dinâmica em contínuo movimento que funciona impulsionado por fatores instintivos, por motivações psicológicas, mas que inclui a conduta ${ }^{8}$.

Por ocasião do nascimento de um bebê que necessita de cuidados especiais, os pais vivenciam todo o processo permeado pela ambivalência de sentimentos em que o medo e a esperança predominam ${ }^{16}$. A ambivalência é a relação, o vínculo com um objeto total em que 0 amor e 0 ódio estão dirigidos para 0 mesmo objeto. 0 sentimento de culpa é uma complicação resultante do sentimento de ambivalência, pelo fato de se odiar um objeto amado, o que provoca dor moral, caracterizando a situação de depressão e melancolia. A dor moral (sentimento de pena) e a culpa sempre estão juntas ${ }^{8}$.

Porém, podemos perceber o sentimento de esperança nas falas das participantes, mesmo que em alguns momentos a condição do recém-nascido seja atribuída a algo divino:

... Acredito que tudo que está acontecendo "faz parte Dele", me apeguei muito a Ele...tenho muita fé que tudo vai passar (mãe-'Águia').

... É só o que eu tenho, muita fé e estou tentando pegar força, porque eu sou uma pessoa que tem muita fé em Deus e eu coloquei ela nas mãos Dele...(mãe-'Andorinha').

As mães não primíparas revelaram a preocupação, tristeza, a falta e o sentimento de estarem "divididas" entre o filho internado e os outros que ficaram em casa. Essa condição a diferencia das puérperas que estão experienciando a maternagem pela primeira vez, podendo intensificar o sofrimento: 
... Eu já fiquei aqui (Casa da Mamãe) do meu primeiro filho...está sendo muito difícil...agora é diferente, porque da outra vez eu não tive que deixar nenhum em casa...(mãe-'Coruja').

... Está muito difícil por causa de eu ter que deixar os meninos que eu tenho em casa e também não posso deixar ela aqui...(mãe-'Arara').

As principais preocupações relatadas em outros estudos são o cuidado com a casa e com as outras crianças, especialmente com a saúde daquelas que estão internadas. As mães ficam ansiosas pela vontade em tê-las saudáveis em casa ${ }^{17-18}$.

As puérperas também explicitaram em seus discursos a tristeza, pesar e pavor causado pelo aparato tecnológico presente na unidade neonatal:

Foi ruim ver ela daquele jeito, trancada...fiquei triste de ver ela naquela incubadora...eu não gostava de ver, eu nem ia ver muito...fui ver agora que ela não está com nada, mas quando ela estava no CPAP, eu nem ia ver ela muito porque tinha vontade de chorar, de ver ela daquele jeito (mãe-'Beija-flor').

... Foi ruim ver ela na incubadora... primeiro tinha visto ela só no berço, depois ela foi para o CPAP e eu só ia ver uma vez por dia..eu não gostava...(mãe-'Sabiá').

As dúvidas mais freqüentes da mãe e de seus familiares relacionam-se principalmente ao aparato tecnológico, aos cuidados de enfermagem, à identificação da equipe que atua na unidade e à terminologia empregada nas informações ${ }^{17-18}$.

Diante do significado e do que representa a internação de um filho recém-nascido, percebemos a importância e a necessidade do profissional de saúde voltar-se nesse momento para os sentimentos expressados pela mãe, tendo em vista a repercussão destes no processo de hospitalização.

Os enfermeiros precisam envolver-se com as mães de filhos internados, logo após o parto, pois o fato de serem "esquecidas" em um momento em que estão fragilizadas física e psicologicamente pode ser a situação responsável por sentimentos capazes de atormentá-las, como a perda se seu filho. Esta situação interfere na recuperação pós-parto e na construção do vínculo afetivo com o bebê.

Aspectos sociodinâmicos da adaptação da mãe à experiência da hospitalização do fil ho

Quanto ao tempo de vivência dessa experiência e permanência na Casa, quatro mães já estavam, no início do estudo, há pouco mais de um mês, duas há alguns dias e três tinham acabado de chegar na "Casa da Mamãe", quando foram convidadas a participar da pesquisa. As entrevistadas apontaram o primeiro dia como sendo o momento mais difícil, ao chegar à Casa e não conhecer ninguém; no entanto, afirmaram:

o primeiro dia é ruim, mas depois melhora...depois a gente vai se acostumando.... (mãe-'Sabiá').

A hospitalização do recém-nascido promove uma inevitável e precoce separação mãe-filho, acarretando sentimentos de luto e reações de desajuste para a mãe, passando, com o decorrer do tempo, por um processo adaptativo até chegar à condição de equilíbrio ${ }^{19}$.

Entendemos que, com a percepção de que é melhor para o filho permanecer sob cuidados e também pela progressão do tratamento e recuperação, a mãe passa a aceitar a condição do bebê e o seu papel de acompanhante:

... Agora já estou me acostumando, tem que ver o que é melhor para o bebê...é só saber levar...eu já me conformei, eu quero levar ele com saúde (mãe-'Bem-te-vi').

... Hoje já estou bem melhor...só em ver que minha filha está se recuperando, está reagindo bem...(mãe-'Beija-flor').

Assim, percebemos que as mães que estavam há dois ou três dias na Casa pareciam mais deprimidas do que as que estavam há mais tempo. Atribuímos a esta diferença fatores como: o quadro clínico dos bebês das mães que permaneciam há mais ou menos um mês na Casa estava apresentando melhoras; a puérpera que se encontrava na fase inicial de hospitalização de seu filho não se havia adaptado ou ainda estava na fase de adaptação/aceitação da nova experiência; as mães que demonstravam um quadro de bem-estar aparente poderiam ter encontrado mecanismos de enfrentamento à crise, como por exemplo, a formação de novos vínculos.

A condição de estar em um ambiente novo, convivendo com pessoas desconhecidas, é fator gerador de estresse para a mãe, principalmente por se distanciar daqueles de seu convívio, que normalmente lhe trazem segurança. Daí a necessidade da formação de novos vínculos. 0 vinculo é sempre um vínculo social, mesmo sendo com uma só pessoa. Relaciona-se posteriormente com a noção de papel, de status e de comunicação. Portanto, todos os vínculos são formas de comunicação ${ }^{8}$.

As participantes revelaram que o fato de estarem na "Casa da Mamãe" proporcionou-lhes o estabelecimento de amizades, cujos vínculos podem permanecer mesmo após a alta do bebê. Afirmaram o quanto foi importante a ajuda que receberam uma das outras e que houve troca de apoio, força, diálogo, fundamentais para a superação da crise vivenciada nessa experiência:

A gente se deu muito bem, parecia que a gente já se conhecia, que já éramos amigas há anos...quando eu estava no canto triste, ela me dava força, quando era ela, eu dava força para ela...(mãe-'Beija-flor').

... Eu acho bom aqui na Casa, é melhor do que lá (hospital)...a gente arranja mais amiga...eu gosto de fazer amizades...(mãe-'Sabiá).

Cada vínculo, mesmo que semelhante com sujeitos diferentes, tem um significado singular para cada indivíduo. Uma relação adulta normal é aquela caracterizada pelo objeto diferenciado, ou seja, que ambos - sujeito e objeto - são livres e não dependem totalmente, podendo assim trazer benefícios para os mesmos ${ }^{8}$.

Portanto, a formação e manutenção desses vínculos são fundamentais para a superação das dificuldades resultantes dessa experiência. Entre as principais dificuldades enfrentadas, as participantes revelaram o fato de estarem longe da família e, principalmente, dos outros filhos: 
... No começo é sempre mais ruim porque a gente fica longe da família e tudo...As mães que chegam lá (Casa) só sabem chorar, comigo não foi diferente...(mãe-'Bem-te-vi').

Vivenciar o puerpério é uma experiência complexa que insinua mudanças dentro do sistema familiar e em cada um dos seus membros. A evolução positiva ou negativa destas transformações depende dos recursos internos da família, do seu nível socioeconômico, do apoio da comunidade e de outras redes ${ }^{20}$.

0 marido/companheiro foi citado pelas puérperas como 0 membro que mais tinha prestado apoio/suporte nesse momento e, em segundo lugar, a mãe (avó da criança):

... O pai dela vem sempre, fica trazendo notícia dos meus pais...minha mãe já veio também..a gente fica mais conformada...(mãe-'Sabiá').

... Ele (marido) está me dando muita força. Disse que não deixa eu ir embora sem levar a filha dele junto, disse que não aceita...ele é muito bom...pede para eu ter paciência...está cuidando sozinho dos outros quatro pequenos que estão em casa...(mãe-'Arara').

Não podemos deixar de citar aqueles familiares que inconscientemente dificultam o processo de desenvolvimento de mecanismos de enfrentamento da situação de crise, pois durante as entrevistas foram relatados casos em que a sogra e até o próprio marido insistem para a puérpera retornar ao lar.

No entanto, também foram revelados aspectos positivos quanto à possibilidade de acompanhar o filho, permanecendo na "Casa da Mamãe", que certamente contribuíram na adaptação da mãe à experiência. Estar mais próximo do filho, recebendo informação sobre seu estado de saúde e ainda podendo oferecer a ele leite materno, é um exemplo desses aspectos:

...Aqui é legal, as meninas são legais (aux. de enfermagem)... mas é que a gente só se sente a vontade mesmo na casa da gente... Também não é tão ruim porque a gente está lá (hospital) toda hora, sabendo notícia, está tirando leite, está vendo o bebê...não é essa coisa toda não... (mãe-'Gaivota').
... Agente pedea Deus que chegue a hora de irparalá(hospital) e poder está encostado nela (sua filha)... (mãe-Arara').

0 vínculo estabelecido entre a mãe e o bebê é fundamental para o relacionamento posterior. A união entre a mãe que amamenta o seu filho é física e espiritual. 0 relacionamento da amamentação parece surgir espontaneamente. É um amor à primeira sugada, começando pela compatibilidade física até formar um vínculo, no qual não serão mais dois estranhos e estarão amarrados por um amor verdadeiro e troca de prazer. Observa-se que mãe e bebê precisam um do outro física e emocionalmente. 0 bebê tem a necessidade física de leite, além de necessitar do contato com a mãe, do amor, da tranqüilidade obtidos através dos sentidos, especialmente da boca, que é extremamente sensível ${ }^{8,21}$.

A partir dessas afirmativas, percebemos que se torna necessário que devida atenção esteja voltada a essas mães, no sentido de minimizar as angústias vivenciadas nessa situação de estresse, assim como favorecer a adaptação das mesmas às mudanças físicas e psicossociais envolvidas no processo da hospitalização do filho recém-nascido.

\section{CONSIDERAÇÕES FINAIS}

Consideramos que o perfil de mãe adolescente, proveniente da zona rural, que teve parto prematuro e que tem outros filhos, só agrava a experiência de ser puérpera com um filho hospitalizado.

Entendemos que as condições da mãe mais dificilmente observadas exigem sensibilidade e afinidade da equipe de enfermagem para detectá-las, pois podem ser expressas por sentimentos, muitas vezes não verbalizados. Portanto, estes sentimentos precisam ser percebidos pelos profissionais que cuidam destas mulheres, pois irão facilitar a prestação de um cuidado integral, além de permitir o estabelecimento da confiança, a aceitação e a satisfação da mãe.

A compreensão das relações e dos vínculos estabelecidos pela mãe com seus familiares e o grupo no qual está inserida configura-se em um dos primeiros passos para que os enfermeiros possam favorecer a adaptação das mesmas ao processo de hospitalização do filho recém-nascido.

\section{Referências}

1. Ministério da Saúde (BR). Parto, aborto e puerpério: assistência humanizada à mulher. Brasilia(DF); 2001.

2.Barbosa LP. A vivência de crises no ciclo gravídicopuerperal. [dissertação de mestrado]. Fortaleza (CE): Departamento de Enfermagem/UFC; 1998.

3. Gonçalves R. Transformar-se enquanto mulher: um estudo de caso sobre a vivência do período pós-parto. [dissertação de mestrado]. São Paulo (SP): Escola de Enfermagem/USP; 2000.

4. Bousso RS. Buscando preservar a integridade da unidade familiar: a família vivendo a experiência de ter um filho na UTI pediátrica. [tese de doutorado]. São Paulo (SP): Escola de Enfermagem/USP; 1999.

5. Santos AF, Campos MA, Dias SFP, Cardoso TVM, Oliveira ICS. 0 cotidiano da mãe com seu filho hospitalizado: uma contribuição para a enfermagem pediátrica. Esc Anna Nery Rev Enfermagem 2001dez; 5(3): 325-34.

6. Rocha RG, Silva RO, Handem PC, Figueiredo NMA. Imaginário das mães de filhos internados em UTI-neonatal no pós-parto: contribuições para a enfermagem. Esc Anna Nery Rev Enfermagem 2004 ago; 8(2):211-16.

7.Marins J, Bicudo MAV. Pesquisa qualitativa em psicologia: fundamentos e recursos básicos. São Paulo(SP): Moraes/EDUC; 1989.

8. Pichon-Rivière E. Teoria do vínculo. $6^{\mathrm{a}}$ ed. São Paulo(SP): Martins Fontes; 2000.

9. Ministério da Saúde (BR). Conselho Nacional de Saúde. Comissão Nacional de Ética em Pesquisa-CONEP. Resolução n 196/96: sobre pesquisas envolvendo seres humanos. Brasília(DF); 1996. 
10. Ministério da Saúde (BR). Saúde e desenvolvimento da juventude brasileira: construindo uma agenda nacional. Brasília(DF); 1999.

11. Monteiro DLM, Cunha AA, Bastos AC. Gravidez na adolescência. Rio de Janeiro(RJ): Revinter, 1999.

12. Ministério da Saúde (BR) Gestação de alto-risco: manual técnico. 4. ed. Brasília, 2000.

13.Brum EHM de, Schermann L. Vínculos iniciais e desenvolvimento infantil: abordagem teórica em situação de nascimento de risco. Cienc Saúde Colet 2004 abr/jun;9(2):457-67.

14. Scochi CGS, Kokuday MLP, Riul MJS, Rossanez LSS, Fonseca LMM, Leite AM. Incentivando o vínculo mãe-filho em situação de prematuridade: as intervenções de enfermagem no Hospital das Clínicas de Ribeirão Preto. Rev Latino-am Enfermagem 2003 jul-ago; 11(4):539-43.

15. Maldonado MT. Psicologia da gravidez, parto e puerpério. $16^{\mathrm{a}}$ ed. São Paulo(SP): Saraiva, 2002.

16.Tronchin DMR. A experiência de tornarem-se pais de recém-nascido prematuro. [tese de doutorado]. São Paulo (SP): Escola de Enfermagem/USP; 2003.

17.Chagas JRP, Souza TV. As principais preocupações referidas pelas mães acompanhantes durante a internação dos seus filhos. Anais do $2^{\circ}$ Seminário de Saúde da Criança e Adolescente; 2001, Rio de Janeiro(RJ): EEAN/UFRJ, 2001.

18. Rocha MP, Silva GRG, Vasconcelos PCO. Internados na unidade de terapia intensiva neonatal: um desafio para a enfermagem. Anais do $2^{\circ}$ Seminário de Saúde da Criança e Adolescente; 2001, Rio de Janeiro(RJ): EEAN/UFRJ; 2001.

19. Santoro JW, Santoro A. Reações psicológicas e processo adaptativo de pais de recém-nascidos pré-termo e de muito baixo peso em Unidades de Terapia Intensiva Neonatal. Rev Paul Pediatr 2002 abr;20(2): 95-101.
20. Quintero Velásquez AM. Câmbios en la dinâmica familiar durante la gestación y el posparto. Invest Educ Enferm 2000 mar;15(1):109-19.

21.Pinheiro AKB. 0 desmame precoce vivenciado por mães adolescentes. [disssertaçãode mestrado]. Fortaleza (CE): Departamento de Enfermagem/UFC; 1998.

\section{Nota}

a Extraído da Dissertação de Mestrado "Abordagem grupal a puérperas com filhos recém-nascidos hospitalizados", Universidade Federal do Ceará, 2005.

\section{Sobre as Autoras}

\section{Maria Adelane Alves Monteiro}

Enfermeira. Mestre em Enfermagem em Saúde Comunitária-UFC. Especialista em Enfermagem Obstétrica e Médico-Cirúrgica e Enfermeira da Santa Casa de Sobral-CE.

\section{Ana Karina Bezerra Pinheiro}

Enfermeira. Doutora em Enfermagem. Docente do Departamento de Enfermagem da Faculdade de Farmácia, Odontologia e Enfermagem FFOE/UFC

\section{Ângela Maria Alves e Souza}

Enfermeira. Doutora em Enfermagem. Docente do Departamento de Enfermagem da FFOE/UFC. Membro do grupo de pesquisa GRUPPSUFC e Coordenadora do PLUS+ - Projeto Integrado de Pesquisa e Extensão em Perdas Luto e Separação. 